\title{
El Eterno Retorno de Nietzsche Hacia una nueva interpretación relacionada con la esperanza por lo Nuevo *
}

\author{
Nietzsche's Eternal Return Towards a new interpretation related to hope \\ for the New.
}

\author{
Por: Ruido, Pablo Gabriel * \\ Universidad Nacional del Nordeste \\ E-mail: pabloruido@hotmail.com
}

Fecha de recepción: 17/03/2020

Fecha de aprobación: 20/04/2020

DOI: $10.30972 /$ ach.054321

\section{Resumen}

El presente es un trabajo de investigación acerca del concepto "eterno retorno" de Nietzsche, revisando las distintas interpretaciones que se han formulado las cuales consideraremos como clásicas (en nuestro caso: heideggereana y deleuzeana) en torno a tal concepto pudimos identificarnos más fuertemente con la perspectiva deleuzeana, que la que más se adecúa nuestra hipótesis. Sin embargo, esto no implica una cerrazón, atento a que la idea central del trabajo es aportar una visión novedosa a lo ya dicho. Hemos procurado realizar una relectura a la concepción del eterno retorno, buscando una definición positiva sobre la misma, tratando de acercar esta concepción filosófica no solo a una interpretación individual, sino al ámbito colectivo del humano y relacionándola con el eterno anhelo por lo nuevo que postula Nietzsche. Podríamos arriesgar que el eterno retorno es la imposición, los valores morales, las doctrinas, las verdades, la rutina de lo cotidiano, y lo nuevo es aquello que viene a romper con todo esto, es la llegada del trans-hombre, aquel que es capaz de crear sus propios valores.

Palabras claves: Eterno; Retorno; Repetición; Nuevo; Trans-hombre.

\footnotetext{
* El presente trabajo surgen en marco de la cátedra Seminario I. Análisis de una obra filosófica del año 2019. Agradecimiento a Diel Lucas, por sus saberes y acompañamiento.

* Estudiantx de la Licenciatura en Filosofía de la Facultad de Humanidades (UNNE).
} 


\begin{abstract}
This work is an investigation related to Nietzsche's concept 'eternal return'. It covers the different elucidations that have been stated as the classical ones; in this case, Heidegegerian and Deleuzian. Regarding the concept of 'eternal return', we mostly coped with the Deleuzian perspective, which is more related to our hypothesis. Nonetheless, the previous statement does not imply a close thought since the main idea of this paper is to give a novel sight to the already said. From our reading and analysis, we tried a 'turn of the screw' on the conception of the eternal return by looking for a positive definition on it and by trying to approach this philosophical conception not only to an individual point of view, but also to the collective side of the human being. After relating the conception to the eternal desire for the new Nietzsche's assumptions we can risk to state the following: the eternal return refers to the compulsion, to moral values, to doctrines, to the truth, to the routine of the mundane. Thus, we can state that the novelty is what comes to break all the above; it is the arrival of the trans-man, who is capable of creating his own values.
\end{abstract}

Key words: Eternal; Return; Repetition; New; Beyond-Man.

\title{
Cómo citar este artículo:
}

APA: Ruido, P. G. (2020) Eterno Retorno de Nietzsche Hacia una nueva interpretación relacionada con la esperanza por lo Nuevo, Acheronta, 5, 134-155. Recuperado de: (agregar dirección web)

\section{Introducción:}

El tema elegido para el desarrollo del presente artículo es el eterno retorno de Nietzsche. Este tema, concepto, o concepción ha tenido a lo largo de la historia una relevancia destacable, ya sea en ambientes filosóficos, académicos o incluso religiosos/teológicos. La idea del eterno retorno posee como el mismo Nietzsche la 
Abril 2020.

describía un peso tremendo e inusitado (la carga más pesada) comparable solamente a los grandes debates filosóficos que han acompañado al ser humano al correr de su existencia. La focalización en el tema procura el objetivo de comprender o lograr interpretar qué nos quiso decir Nietzsche en sus pocos aforismos donde ha tratado lo que describe como su pensamiento más pesado. Sin dudas, Nietzsche trajo una explosiva vitalidad a un concepto más que antiguo, y con ello propició cientos de estudios y formulaciones sobre qué es el eterno retorno de lo mismo.

Elegimos, entonces, apropiarnos de este tema porque creemos que atraviesa múltiples momentos de nuestra vida: la pregunta por la muerte, la pregunta por la vida, por el sentido de la misma, los cuestionamientos existencialistas con respecto a la rutina, el cansancio y el aburrimiento, el vitalismo, y muchas otras preguntas o temas que nos han interceptado en medio de la noche podrían encontrar una respuesta (o más preguntas) en el eterno retorno, es así como este pensamiento se transforma en un aporte inconmensurable a la filosofía.

\section{El inicio de un Eterno Retorno}

La idea del Eterno Retorno no es original del autor Alemán, al contrario, es un concepto o concepción del mundo y el tiempo que nos remonta incluso años anteriores al comienzo del calendario cristiano. La escuela estoica es una de las primeras en manifestar esta idea en occidente, en la cual se planteaba que el mundo se creaba, y al correr de un determinado tiempo se extinguía y consumía en el fuego primigenio para volver a resurgir, en este nuevo mundo solamente se sucederían exactamente los mismos actos que ya se habían sucedido, de esta manera se seguiría repitiendo. También el eterno retorno suele identificarse con el dibujo, o símbolo del "uroboros", donde se puede observar una especie de serpiente o dragón, comiéndose su propia cola pero girando sobre sí y formando un círculo, representando así aquello que nunca acaba, y que vuelve a repetirse eternamente, volviendo siempre sobre sí a las mismas posiciones. Este símbolo nos transporta incluso a la época del antiguo Egipto, donde en las pirámides se podían observar estos dibujos, como así también a 
distintas culturas como la nórdica, y como la griega o la romana. El mito de Sísifo es uno de los ejemplos más didácticos, concretos y antiguos que nos hacen visualizar la idea de una repetición eterna, en este mito Sísifo es obligado a cargar una piedra hasta la cima de una colina, la cual al momento de llegar a la cima volverá a caer hasta la llanura y Sísifo deberá emprender nuevamente su recorrido, una y otra vez, sin solución.

En el mundo y las religiones orientales la idea del eterno retorno, continua subyacente en sus concepciones mas contemporáneas, pero la repetición trae consigo la posibilidad del perfeccionamiento. En occidente se supone que se ha superado la idea del eterno retorno, pero esto se debe a la necesidad de nuestra mitad del planeta de pensar todo en términos opuestos, por tal, pensar apenas una idea del eterno retorno traería consigo la imposibilidad de aceptar la concepción del libre albedrio que profesan actualmente nuestras religiones más masivas y populares.

En la actualidad podemos ver como la fascinación por el tiempo, e ideas símiles a la formulada se llevan protagonismo de interminables libros, películas, comics, series, comentarios en blogs y en la web, entre otras tantas esferas. ${ }^{1}$

Posiblemente sea de las antiguas ideas y raíces orientales de donde Nietzsche encontrara los primeros esbozos para su propia concepción del eterno retorno.

Hasta ese momento nos encontramos con una concepción probabilística del tiempo (aunque en algunos casos no sea explicitado así) donde se busca dar fundamento de que en nuestro universo todo va a volver a repetirse indefectiblemente, esto trae consigo una respuesta matemática, y lazos con la física y otras ramas de la ciencia que estudiarán el fenómeno del tiempo.

\section{La transvaloración del Eterno Retorno}

\footnotetext{
1 Alguno de los casos paradigmáticos que podríamos nombrar es la serie alemana "Dark" donde abiertamente se plantean ideas acerca de la posibilidad o imposibilidad de cambiar el tiempo, o mejor dicho cambiar los sucesos del pasado, para también así modificar la forma en que las cosas ocurrirán en el futuro o presente mismo, así nos proponen la circularidad del mismo, rompiendo con la linealidad de los actos, e incluso se realizan menciones abiertas a la filosofía de Nietzsche. Por otro lado, en la serie estadounidense, True Detective la idea de la infinita repetición de lo mismo se encuentra subyacente y latente a lo largo de la misma.
} 
Es curioso notar cómo un concepto que lleva consigo la palabra eterno, posee en sus interpretaciones más antiguas la idea que el tiempo tiene un principio y un final, una linealidad del tiempo, o un tiempo circular pero idéntico, lo cual nos hace vislumbrar o preguntarnos que si lo eterno pero igual, al fin y al cabo ¿'es eterno?, ¿donde se encontraría la eternidad si no es más que lo mismo? Aquí la eternidad no solo aparece como una cuestión secundaria a la repetición, si no como una amenaza y resignación a los designios del universo. Desde nuestra posición entendemos que Nietzsche con todas sus contradicciones, idas y vueltas, y claros-oscuros, pareciera querer romper también con la idea clásica del eterno retorno, e intenta al menos desde nuestro punto de vista, mostrarnos que el eterno retorno no es la repetición, es decir un principio y final continuo, sino la eterna caída del hombre en las mismas concepciones morales, en las mismas mentiras transformadas en verdad, en la rutina establecida como lo correcto, como bien podemos observar en su aforismo doscientos ochenta y tres (283) de La gaya Ciencia cuando expresa "Saludo a todos los signos que anuncian el despuntar de una época viril, guerrera, que por sobre todo rinde honor nuevamente a la valentía! Pues ella ha de abrir el camino para una época superior y ha de acumular la fuerza que aquélla necesitará algún día -aquella época que lleva el heroísmo al conocimiento y hace la guerra a causa de pensamientos y de sus consecuencias. Para eso se requiere por ahora de muchos y valientes hombres preparatorios, que sin duda no pueden brotar de la nada $-\mathrm{y}$ mucho menos de la arena y la baba de la actual civilización y cultura de las grandes ciudades: hombres que saben ser silenciosos, solitarios, decididos, felices y constantes con actividades imperceptibles; hombres que por inclinación interior buscan en todas las cosas lo que en ellas haya de superarse..." aquí nuestro autor viene criticar fuertemente la cultura y la educación, actual, repetitiva, babosa, sin alguna base fuerte, viene a (hacer el intento) de reformular estos valores, o quiere mostrar al hombre aquellas herramientas para hacerlo, acá, lo realmente grave parece ser la eternización, el "siempre lo mismo" (Nietzsche, 1990), y la repetición ocupando el lugar de la resignación, pero también es la que da lugar a la esperanza: el camino es tan largo que aún podemos evitar que todo sea igual, que todo se repita. 
En este sentido podemos advertir como Nietzsche toma un concepto que hasta el momento se relacionaba más con la factibilidad de los hechos y sucesos, para generar una poderosa maquinaria y estructura de cuestionamiento a las morales impuestas. Si bien, entonces, no concibió la idea del eterno retorno, tomó las que ya existían y las forzó a dar un giro de ciento ochenta grados, puso de cabeza la cuestión.

Consideramos que existen dos corrientes de interpretación clásicas acerca de como asimilar el concepto del eterno retorno: una es el famoso sí a la vida, decir sí a todo, más allá de que se vaya a repetir eternamente en sentido hipotético, aceptarlo ya que estamos haciendo de nuestras vidas aquello que seriamos capaces de soportarlo para siempre, a esta concepción podríamos llamarla vitalista. En dicha interpretación podríamos simbolizar al tiempo de forma circular, pero como la posibilidad del cambio permanece abierta, es aquí el intento de asimilar la gravedad de la eternidad, pero la liviandad del ser humano, es tan efímera nuestra vida que deberíamos vivirla de tal manera que podríamos soportarla por siempre. Utilizando este variable de cuestionamiento moral, nos hace pensar que nosotros como seres individuales solo pasaremos una única vez por el círculo del tiempo, no volveremos a los mismos lugares ni momentos. Aquí la idea del eterno retorno parece funcionar más como metáfora y guía ética que como afirmación de un ciclo real.

Por el otro lado, podemos encontrar su contracara, el pesimismo de pensar que todo va a volver, que entonces todo carece de sentido, ya que todo se va a repetir, estamos inmiscuidos en un circulo que viene y va, que nunca se detiene ni cambia su dirección, esta visión es la que habitualmente se relaciona con una concepción cuasi matemática, donde se cree que todo realmente volverá a ocurrir. En esta segunda interpretación el tiempo también podría ser considerado circular, un círculo temporal por el cual volvemos a pasar infinita cantidad de veces. Iremos y pasaremos por el mismo lugar, lo que nos llevaría indefectiblemente a la repetición de todos los paisajes, hasta de aquellos pequeños detalles que habíamos olvidado.

En cualquiera de las dos opciones, vale la pena citar al mismo Nietzsche en su aforismo trescientos cuarenta y uno (341) de La Gaya Ciencia, sería pertinente formularnos frente a todo y en cada caso, la pregunta: “¿quieres esto una vez más e 
Abril 2020.

innumerables veces más?», irecaería sobre tu acción como la mayor gravedad!" (1990).

\section{Heidegger y Deleuze}

Existe una gran diversidad de autores que han expuesto sobre el concepto del eterno retorno, buscando nuevos caminos e interpretaciones, miradas alternativas, enlaces con otros conceptos. Por una cuestión temporal nos resulta imposible si quiera leer las obras completas dedicadas al eterno retorno de un solo autor, pero sí, hemos abordado un paneo general sobre las distintas interpretaciones que se encuentran del mismo. Entre ellos podemos destacar a Martin Heidegger (2013), quien adhiere y toma para sí la idea del eterno retorno. Desde una perspectiva ontológica ubica al eterno retorno como el pensamiento más importante de Nietzsche, reafirmando las palabras del autor. Heidegger, además de utilizar la idea para sus propias definiciones de ser y ente, pareciera adherir desde un punto de vista metafísico, cuestiona a aquellos que lo ven solo como una metáfora (o guía ética como hemos mencionado) y una pregunta a realizarse, ya que le estamos quitando volumen a la idea más pesada, por eso mismo para Heidegger la idea del eterno retorno contiene una enunciación sobre la totalidad del ente, el desconsuelo que provoca semejante doctrina es automático, y por eso la rechazamos apenas la oímos (Heidegger, 2013). Heidegger es uno de los autores que, si hubiéramos de ubicarlo, se encuentra más cercano a la concepción probabilística y matemática, no porque creyera que las cosas de verdad volvieran a repetirse, sino porque para él la idea iba mucho más allá de una cuestión meramente ética. De la propuesta Heideggeriana surgirán muchas interpretaciones que sí conectarán a esta corriente relacionada con la factibilidad del eterno retorno. Para Heidegger el ser desea siempre la superación de su poder (voluntad de poder) y por ende por mas rica o plena que pueda ser una vida siempre se retorna sobre si para crecer, es decir, la voluntad de poder y el eterno retorno según Heidegger funcionan como verdadero motor movilizador, y no solo como un tipo de precepto moral. Para Heidegger la 
voluntad de poder es el carácter esencial del ser. Heidegger mismo argumenta en su libro "Nietzsche", tratando de explicar a éste, que el tiempo es infinito, sin embargo, el hombre, y nuestro mundo no, por tanto en la situación de tiempo infinito, vamos a repetirnos, es más, al ser el tiempo sin fin, ya todo este mundo se ha repetido infinitas veces, ya que nuestras posibilidades no son infinitas.

Otro de los autores que ha abordado la idea del eterno retorno es Gilles Deleuze (2002), a quien podríamos ubicar más cercano a la concepción vitalista del concepto, el eterno retorno no es la repetición de lo mismo, como una cuestión física, sino mas bien es la aceptación de lo que viene, pareciera colocarse así en un extremo contrario a lo planteado por Heidegger. Entonces, no se trata de una ley natural, más bien se trata sobre el caos en el que reside la naturaleza (Deleuze, 2002). La interpretación de Deleuze nos conduce hacia la afirmación de la vida, y del ser en su aceptación del devenir, es tal vez resignación positiva a que el caos va a ocurrir, y que nosotros somos parte de ese caos, es también aquello que en palabras criticas de Heidegger es "reducir" al eterno retorno a una pregunta, pero esta misma te acompañara por el resto de tu vida como la carga más pesada. Deleuze también rescata en cierto sentido las concepciones orientales del eterno retorno, en sus obras desarrolla la teoría de que la repetición traerá consigo la posibilidad de la mejora y el perfeccionamiento, es decir, el eterno retorno no es la vuelta de lo mismo, sino la posibilidad de que en la vuelta uno pueda cambiar el camino, o caminar distinto. Complejizando aún más, el mismo camino quizás no se repite nunca, pero tomando para nosotros ideas del propio Nietzsche, lo que se repite en realidad son los sometimientos a los distintos tipos de morales, nos sometemos a una rutina impuesta, y es ahí donde todos los días se vuelven un eterno retorno de lo mismo. Para Deleuze, la afirmación de la vida, es decir, la afirmación del eterno retorno es placer, es goce, en cambio la negación traerá justamente lo contrario, tristeza, dolor, negación de la vida misma. Es aquí donde la actitud del que afirma el eterno retorno, afirma la vida, es igual a la actitud del súper hombre, y se empieza a convertir en este: es la actitud de un niño, el que acepta el azar, el juego, el que dice si, que jamás pierde la capacidad de asombro. 


\section{Re significación del eterno retorno}

Sirviéndonos de las dos concepciones mas fuertes sobre la misma, sobre todo de la deluzeana pero tratando de aportar elementos, en este sentido queremos re significar la positividad o vitalidad que se le pueden otorgar a los pensamientos precedentes. En este sentido, el problema rector del escrito podría formularse del siguiente modo: ¿Se puede reinterpretar de manera positiva la visión Deluzeana del eterno retorno en relación a la idea Nietzscheana de lo nuevo?

Hemos elegido hacer caso a las recomendaciones del mismo Nietzsche, y en vez de buscar interpretaciones originales del autor, preferimos tomar sus escritos para enunciar, o intentarlo, propias ideas, construcciones, y futuras deconstrucciones de los conceptos.

En este sentido, según nuestra fórmula, el tiempo parece configurarse de manera circular, se busca romper con la linealidad del tiempo. Del tiempo como creación del hombre, y entender al tiempo como un todo que nos interpela, es el tiempo el que seguirá estando aquí o allá cuando nosotros no, el humano es lo pasajero y efímero, nosotros somos un instante en la eternidad, por eso debemos entender al tiempo circular en un tamaño expansivo y en eterno crecimiento, pero por merito propio, no por intercesión humana, esto hace que los hombres y mujeres jamás volvamos a pasar por los mismos lugares, pero la idea del eterno retorno como tal también nos fuerza constantemente a realizar una valoración distinta por el instante, por lo fugaz, si todo fuese eterno nada vale más que lo efímero, nada vale más que dotar de carga positiva lo pequeño, el detalle, pero Nietzsche parece ir mas allá, ¿que harías si este instante se repitiera para siempre? ¿Seguirías haciendo lo mismo o cambiarias?, Nietzsche parece plantearnos que dotemos de eternidad el instante, que hagamos valer lo pequeño, el eterno retorno es ese cuestionamiento que guiarnos o hincarnos en la conciencia a cada acción. El ser es el instante y por tanto no le queda más que valorar su propio tiempo y estadio en el mismo, a lo sumo, por sus herederos, pero no mucho más allá, ni siquiera nuestra mente nos deja preocuparnos por un 
futuro lejano, y justamente la valoración del instante y lo fugaz es la valoración de la vida humana, es lo frenético y pasional, es decir que si por qué no nos alcanza el tiempo para negarnos a lo que se nos presenta, y por supuesto es también a la vez, en este sinuoso camino, ir deconstruyendo lo establecido y construyendo lo propio, construyendo pasiones, construyendo nuestro devenir inmediato, construyendo vida.

Al no existir el eterno retorno como tal, como acciones y momentos concretos que se repiten en la vida de un hombre, encontramos entonces que el ser humano se encuentra sometido a distintos tipos de valores morales, de religiones, rutinas, e instituciones de todo tipo, hasta clubes de barrios, educativas, e incluso instituciones del tipo afectivas como la de la amistad, de la familia, del amor, o del trabajo, todas ellas traen consigo valores morales pre configurados y pre establecidos que si bien en ningún momento los aceptamos tácitamente, terminan y terminaran por imponerse en nosotros, cerramos los ojos, nos olvidamos que son una creación del hombre, nos olvidamos que son solamente la mentira más aceptada como bien podría decir Nietzsche y por tal se transforman en verdad, y las normalizamos, las volvemos ley, y todo aquello que se escape a esta ley es considerado la mentira, lo feo y lo malo. Todos esos valores morales son ahora para nosotros lo que está bien, en contraposición, todo lo que sea contrario a ellos, está mal, y por ende, son el mal, solo por el hecho de no contar con la misma aceptación social o colectiva. Es decir, nuestra concepción del retorno eterno implica una visión colectiva del hombre, ya no solo como el individuo que sufre de la pesadez de esta idea y no concibe el sueño, sino ya como grupo, especie, o raza humana, no es un hombre o mujer solo el que padece la rutina eterna, sino toda la humanidad es la que sufre la repetición de los sometimientos que ya han sufrido los otros hombres y mujeres, uno ni siquiera es consciente de que está pasando por lo mismo que ya han pasado generaciones y generaciones pero en su interior acarrea con esa pesadez ¿cuántas veces hemos sentido una especie de deja-vu, cansancio o molestia al realizar algo que quizás hasta ese momento no lo habíamos hecho nunca? cargamos, tal vez con la memoria colectiva de miles de años.

"Esta canción ya se escribió, hasta el mínimo detalle..." 
Esta reinterpretación colectiva también nos permite extrapolar el concepto del eterno retorno un poco más allá de los marcos filosóficos comúnmente acordados, y llevarlos a otras ciencias humanas y sociales como por ejemplo la política. Continuamente vemos y escuchamos como sociedades y pueblos reclaman repetir una y otra vez gobiernos, que incluso siendo de distintos signos políticos se alternan la aplicación de las mismas políticas y recetas que vienen fracasando hace décadas.

Acaso, no son los pobres del mundo, la clase social que estigmatizada por el pasado de sus antecesores se ven obligados a repetir historias interminables veces, y las instituciones que poseen el poder real en el mundo no se cansan de repetir que se es pobre porque es lo que el destino, o alguna otra fuerza mayor (léase dios) les otorgo esto en alguna especie de sorteo de suertes para la vida. Aquí pareciera aparecer Nietzsche para gritarle al pobre, al desamparado, al marginal: "rompe con tus cadenas, con el eterno retorno, lo nuevo te espera".

Es aquí, en la repetición eterna del sometimiento del hombre a los valores morales impuestos, a la verdad, a la normalidad, a la rutina, donde entendemos que Nietzsche encuentra el eterno retorno, el mundo nunca cambia, cambiaran tal vez en la historia del hombre pequeños detalles sin importancia, pero estos hombres pequeños también podrían acarrear historias de lucha contra el eterno retorno, historias inconclusas, fatídicas y fallidas, pero también pasionales, instantáneas y efímeras. Aunque el sometimiento continúa ahí, las cadenas invisibles no se van, a veces incluso cambia la máscara o el nombre de la institución de valores que nos somete, pero en el fondo sigue siendo lo mismo, este es nuestro eterno retorno.

Planteémoslo de otra manera, de que sirve acaso la extensión de la vida, suponiéndola corta, larga, mediana, o eterna, si todos los momentos de la misma nos vemos sometidos inconscientemente a la rutina de lo cotidiano, y no podemos escapar de ello, es más, en general ni siquiera nos damos cuenta del sometimiento y por tanto no podemos ejercer si quiera el intento de librarnos de la misma, nuestra libertad está limitada. 
Es ahí donde la idea del eterno retorno toma una revalorización, cada instante, efímero y fugaz de nuestras vidas solo cobra sentido realmente cuando hacemos algo que creemos vale la pena, Nietzsche planteaba justamente vivir con pasión, valorar la belleza de la vida, y de aquí podemos entender que en cuanto a lo colectivo, la vida de un pueblo, una nación, un grupo, vale la pena cuando luchan, logran, o realizan de manera conjunta la persecución de las condiciones de vida que le permitan también la realización individual del goce de la vida.

De igual manera, la fatalidad del círculo eterno que nos propone Nietzsche, y la pregunta sobre nuestra elección ante semejante abismo, nos está otorgando la posibilidad de otorgarle un propio sentido a la vida, a nuestro círculo, y al mismo tiempo deja sin-sentido a la vida, es decir la vacía para que sean los protagonistas quienes la llenen, es decir indirectamente decreta la muerte de dios, o de toda idea o fuerza mayor, que de forma religiosa o dogmática quisiera dotar de un sentido superior al estadio humano en el mundo. El humano pasa a ser el centro de su propia historia, y a la vez pierde todo valor real en el mundo, el mundo y el universo seguirán siendo cuando el hombre no este, sin embargo el hombre tiene un corto tiempo, y es todo lo que tiene. Declarar la muerte de toda idea superior, todo poderosa, omnipresente es hacer al hombre protagonista, tiene que hacerse cargo de sus actos, porque a la vez es esto todo lo que tiene, ya no puede lavarse las manos, ni mirar hacia el costado, no puede hacerse el desentendido ante la vida que le corre por sus ojos, la arena en el reloj se va terminando, y él es el único responsable de hacer valer esto de alguna forma.

En tanto, otro de los temas centrales en la bibliografía de Nietzsche (1990), y el cual no siempre ( o casi nunca) se asocia al eterno retorno, ya que a primera vista pareciera ser que el autor alemán podía tratar temas totalmente discordantes de una hoja hacia la otra, es el pedido por lo nuevo, o la espera de lo nuevo, como en el aforismo doscientos ochenta y tres (283) cuando Nietzsche dice observar y celebrar las señales de un nuevo hombre, que traerá consigo una nueva época, dejando atrás la actual, de la cual el mismo forma parte. 
Abril 2020.

ISSN 2344-9934

Nietzsche realiza casi una súplica, esperando que llegue el primero de lo nuevo en todos los sentidos, posiblemente entendiera que aquel que puede desligarse de alguna institución de valores también podría hacerlo con las demás. Este pedido realizado por el filósofo alemán se repite a lo largo de toda su obra con distintos nombres, el más conocido de ellos es el súper o trans hombre, este estadio superior es aquel que aún no ha llegado, y que Nietzsche anhela, el que viene no solo a romper con los valores establecidos, sino también a trans valorarlos a todos, a dar vuelta el tablero. Nietzsche compara al súper hombre con un niño, por ser aquel capaz de cuestionar todo, con la inocencia del que no acepta sometimientos.

Ahora bien, la idea un súper hombre, o trans hombre (lo cual consideramos sería una traducción más adecuada para el estilo de Nietzsche) implica entonces un tipo de humano, o un estilo de vida humana no solamente que rompa con lo ya establecido y predeterminado, sino también aquel que le escape a la normalidad, que huya de los lugares comunes, que tenga pavor por la repetición de sus actos. Aquel que se adentra en lo nuevo, en lo inesperado, en lo no conocido es quien justamente no tiene miedo de la repetición, porque a cada instante está aportando a su vida pasión, originalidad, vitalidad en el sentido nietzscheano. Incluso podríamos decir que el trans hombre es más bien un personaje, una máscara, a disposición nuestra, al alcance de nuestras manos pero que no queremos tomarla, es el papel más complicado en esta obra de teatro que es la vida, el mismo Nietzsche decía que todo lo profundo ama la máscara. Quizás, refiriéndose a que para llegar a lo profundo de la vida, al sí, había que tomar este personaje del súper hombre para nosotros, encarnarnos en él y nunca más volver a ser aquello que fuimos, esclavos de normas impuestas por alguien o algo más.

Pues bien, el tiempo no se mide en las agujas del reloj, o en las marcas de la piel, no se podría medir incluso en un calendario, más bien la forma más adecuada de observar, contemplar y entender el paso del tiempo es medirlo en nuestros actos, acaso, aquel hombre o mujer que no hace nada en su vida, no estudia algo que le gusta, no explora el arte, no conoce lugares nuevos, no ha conocido otras fronteras ni otras culturas, no interactúa con otra gente ni consigo mismo, no escribe, no ha 
caminado por el bosque o por la playa, o no ha hecho nada nuevo al alcance de sus posibilidades reales y efectivas ¿han pasado realmente cincuenta años para esa persona?. Obviamente existe una faceta, si se quiere, objetiva, del tiempo, no venimos aquí a discutir esto, pero como bien dice Nietzsche, después del hombre, nada ha pasado, ¿acaso ha quedado alguna huella, alguien recordara, o algo se llevara aquel hombre que durante su vida no ha realizado nada que pueda considera memorable?

Pero esta idea de un trans hombre, como una especie, o forma superior, personaje adaptado a la vida, o al menos más libre del humano actual, claramente parece chocar con la idea de un ente superior y perfecto como es Dios, por eso entendemos que el decretar que dios ha muerto, no solo tiene que ver con la obviedad de atacar a las religiones e ideas enquistadas de hace miles de años en el hombre, sino también con permitirle al humano sentirse liberado, no existen ojos que te estén mirando a cada momento, no existe el juicio constante, ni el dedo índice apuntándote. Romper con la idea de un dios omnipresente y todo poderoso como lo presentan las religiones, no solo le otorga libertad a los hombres y mujeres, sino que carga en sus espaldas el peso más pesado, ahora no hay un dios que haya premeditado y acomodado cada pieza del tablero para que lo que está a punto de ocurrir, ocurra. Ahora, cada hombre y cada mujer en este mundo son responsables de sus acciones, y tiene a su alcance el poder de decidir sobre sí. Al terminar o intentar acabar con la idea de un destino escrito e inmodificable también Nietzsche abre la posibilidad, no solo a la decisión del humano, sino también a uno de sus conceptos favoritos: el azar. Lo nuevo, lo fortuito, y lo azaroso puede presentarse a cada instante frente a nosotrxs, y el exclamar que si ante cada posibilidad, adentrarnos en lo desconocido, afrontar todo siempre hacia adelante, es entonces la muestra más cabal de que estamos vivos. El tiempo está pasando, está ocurriendo, ahora mismo.

En otros pasajes de su obra también hablando del arte o de la música ${ }^{2}$ reconoce que la cultura es un reflejo de la sociedad, de sus etapas y momentos, y reclama que aparezcan músicos y artistas que con curiosidad, imaginación e ingenio puedan romper

\footnotetext{
${ }^{2}$ Se recomiendan los aforismos 103 y 183 de La Gaya Ciencia para ahondar más en el tema de la música, el arte y la cultura.
} 
Abril 2020.

ISSN 2344-9934

con lo típico. En este sentido, el arte necesita nuevamente de la actitud infantil, la creatividad y el juego son los que otorgaran originalidad a las obras, la llamada transmutación de todos los valores de Nietzsche tiene que ver con esto, con la innovación, y no solamente con realizar giros de ciento ochenta grados, ya que sabemos que el mismo era un ferviente militante de la eliminación de los opuestos, o de la aceptación de los mismos, como coexistentes.

En la gaya ciencia(1990), el eterno retorno es un tema recurrente, desde el aforismo número uno (1), donde Nietzsche habla sobre "los maestros de la finalidad de la existencia", podemos notar como Nietzsche nos plantea de forma subyacente que el mundo, o mejor dicho la humanidad en el mundo vive y sobrevive haciendo siempre lo mismo, guiados por el instinto de supervivencia, si bien no realiza una crítica que podría llamarse frontal o severa se deja ver como el mismo parece proponer dejar de lado al menos un rato ese instinto, y lograr reírnos, divertirnos, darle otro tipo de intensidad a nuestras existencias, haciendo valer más una existencia fogosa y corta, que una larga, repetitiva, eterna, aquí no solo está el eterno retorno del hombre y de lo mismo, sino también el deseo de hombres nuevos que puedan romper con estas imposiciones. En su aforismo número cuatro, "lo que conserva la especie" nuevamente nos habla del placer y deseo por lo nuevo. Que se necesitan hombres que enciendan aquellas pasiones adormecidas y que toda sociedad establecida adormece las pasiones (1990). Nuevamente la figura de la sociedad, del hombre en comunidad, anestesiado justamente por verdades aceptadas, es decir por instituciones moralizadoras que creamos y a las cuales les damos el rumbo de nuestra vida, y son aquellos hombres nuevos, creativos, los que pueden romper con esto, o al menos desatar un pequeño incendio, una pequeña llama que despierte nuestras pasiones olvidadas, nuestra pasión por la vida: el vitalismo de Nietzsche no es solamente querer vivir, sino amar vivir de una determinada manera, de aquella que consideremos intensa, pasional, contradictoria, lúdica. En el mundo nietzscheano no es una contradicción haber sido un vitalista y morir joven, como la historia de la filosofía lo ha hecho querer parecer.

Otro ejemplo claro sobre la recurrencia de Nietzsche en la necesidad de la novedad, de lo nuevo, es decir del movimiento como equivalente a vida, se ve en el 
aforismo veintiséis (26), esta vez en un sentido más personal, individual e interno. Nos interpela diciéndonos, preguntándonos, apuntando con el dedo y exigiendo ¿qué es vivir?, y nos arroja con una respuesta tan poco esperada como certera: "significa: ser cruel e implacable contra todo lo que en nosotros se vuelve débil y viejo" (1990). A través de este fragmento rápidamente podríamos deducir que el hombre, que solo vive sometido una y otra vez a los mismos valores éticos y morales, valores que se vuelven viejos, decrépitos, hacen que nuestras vidas dejen de ser vidas, quizás solo estamos sobreviviendo, pero no necesariamente viviendo. Estos valores al ser viejos, también deberían volverse débiles, como dice Nietzsche, y seguramente lo sean, de cimientos poco macizos, de estructuras tambaleantes, a punto de caerse, sin embargo el hombre no tiene la suficiente valentía para tumbarlos, para derribarlos, para destruir y deconstruir. Necesita un hombre nuevo, aquel armado de tanta pasión que sea capaz de derribar todo lo que a su paso encuentre.

En uno de sus aforismos más famosos de La Gaya Ciencia, el numero doscientos setenta y seis (276), Ilamado "Para el año nuevo", Nietzsche expresa lo siguiente: "Aún vivo, aún pienso: aún tengo que vivir pues aún tengo que pensar..." (1990) "-icual pensamiento debe ser para mí el fundamento, la garantía y la dulzura para el resto de la vida! Cada vez mas quiero aprender a ver como algo bello todo lo necesario en las cosas". (1990). Vivir para Nietzsche es también la necesidad y el ejercicio de pensar, este accionar es el que nos permite aceptar, avanzar sin mirar atrás, sin cuestionar las decisiones del pasado sino cambiar las decisiones del futuro, quisiera ser aquel que siempre dice que si, reza Nietzsche, aquel que siempre dice que sí, es el que se construyó el camino de su propia belleza, que no se vuelve viejo, que mantiene la pasión encendida, pues aún tiene mucho que pensar, que decir, pero sobre todo para hacer.

Por una parte, en estos fragmentos podemos percibir en el autor cierta resignación, desazón, aún tengo que vivir, aún pienso pero nada nuevo hay ahí, el año nuevo es un cambio de esos pequeños detalles sin importancia de los que hablábamos, sin embargo, nada realmente nuevo trae consigo. Pero Nietzsche abre una puerta a la esperanza y a lo nuevo, decir que si a todo, el "amor fati": amor al destino, expresado 
Abril 2020.

en este aforismo es una luz de esperanza, porque decir que si a todo lo que venga es también aventurarse a lo desconocido, decir que si a cada fatalidad que se aproxime, buena o mala es abrir la posibilidad a cambiar con la rutina, que lo nuevo se aparezca, que lo nuevo venga a nosotros porque ahora decimos que si a todo, no nos negamos por el hecho de que cierto valor moral nos diga que algo está mal o que no es lo normal.

Vemos como Nietzsche no solamente anhela la llegada de lo nuevo, sino que también concilia la repetición con lo nuevo, rompe con los paradigmas del pensamiento dual, binario, entender que la contradicción no es más que un invento del hombre y que los supuestos contrarios coexisten, es decir todo se repite, el yugo, la sumisión moral, pero eso no nos quita la posibilidad y la esperanza de lo nuevo, y más aún, lo nuevo tampoco es bueno o malo, es simplemente nuevo, y debe permanecer siempre en movimiento para no estancarse y terminar convirtiéndose solamente en nuevos valores morales. El hombre posee una fascinación por catalogar las cosas en sistemas blanco/negro, pero hay belleza en toda la escala cromática, sobre todo en aquello que es nuevo, si lo común fuera lo blanco, aquello más oscuro traería una belleza fascinante, y lo mismo se daría al contrario. El vitalismo de Nietzsche (su famoso "SI" a la vida) es entendido como movimiento, la vida es movimiento, y el movimiento implica novedad, no estar siempre en los mismos lugares, aquello que se estanca, que permanece tieso, aquello que se repite eternamente deja de tener vida.

De esta manera adherimos al autor Alemán, entendiendo que la contradicción es parte natural de nuestra especie, parte de nuestro instinto. Que algunos conceptos se encuentren en supuesta contradicción no significa la exclusión, expulsión o eliminación del "contrario", ya que todos los conceptos no son más que inventos del humano. La coexistencia de supuestos contrarios no solo implica según la visión Nietzscheana aceptarlos, sino entender que existen otros caminos y no solo dos. La originalidad, las pasiones, el sí a la vida, el juego y el azar son las virtudes que nos podrán llevar a nuevos lugares.

De la concepción física/matemática del eterno retorno aceptamos y tomamos que es posible una repetición del mundo y de las vidas que allí existimos, ya que si la 
materia es finita en algún momento se volverían a dar las mismas combinaciones, en un tiempo de lapso infinito la materia finita volvería a repetirse una y otra vez, aunque este ciclo podría tardar millones y millones de años (y hasta acá llegamos porque no somos físicos).

De la concepción ética o vitalista nos apropiamos de la valoración del eterno retorno como guía para la vida, o pregunta guía, para toda acción, evaluarnos o cuestionarnos si aquello que estamos haciendo lo quisiéramos repetir por siempre, aceptar esta idea te hace vivir la vida de manera más consciente, lo cual termina siendo un sí a la vida o al menos el intento de buscar las circunstancias en las cuales nos gustaría decir sí, generar nuestras propias condiciones para poder aceptar lo que venga.

Desde nuestro lugar, queremos aportar que con las lecturas de Nietzsche entendemos que la concepción del eterno retorno funcionaba como columna vertebral y piedra angular de todo su pensamiento, al menos en su etapa de mayor madurez y producción literaria.

La idea del eterno retorno aparece a lo largo de toda la obra de Nietzsche, pero no siempre, e incluso solo en pocas ocasiones mencionada como "eterno retorno", pero que el autor alemán no haga una cita concreta al título de esa concepción no quiere decir que no la esté utilizando, la idea de la repetición y de la sumisión del hombre en los mismos valores morales nos hacen pensar que el eterno retorno no necesita ser nombrado, está ocurriendo ahora mismo, y Nietzsche se encontraba así mismo sumergido en el, clamando porque se termine, porque algo nuevo, intempestivo ocurra. Podemos encontrar cómo, en reiteradas y variadas ocasiones también Nietzsche habla y menciona el devenir de lo nuevo, de lo distinto, aquello que supere lo ya establecido, aquello que viene a romper con los moldes o a darlos vuelta, esta idea que en el punto álgido de su escritura se transformara en la concepción del súper-hombre. Pero no se trata solamente de una pasiva espera por lo nuevo, el autor Alemán nos pide, y nos intenta mostrar el camino, las circunstancias, las formas de las cuales nos podemos servir para ir al encuentro de la novedad, es una súplica para que aquel que se encuentre siendo interpelado por el texto o por alguna de estas ideas se 
Abril 2020.

convierta en el trans hombre, ya que no existe un punto exacto de evolución del humano, ni existe uno o una cierta cantidad de súper hombres, más bien, seguramente, habrá alrededor de nuestro mundo aquellos quienes estén en una lucha constante contra la eterna repetición, y bregando por el azar, por lo nuevo.

Aquí es donde encontramos para nosotros una relación clara entre estos dos conceptos centrales de la filosofía nietzscheana, relación casi filial, ya que a nuestro entender el eterno retorno y lo nuevo (o súper hombre en su versión más concreta) se necesitan uno a otro para subsistir, ya no solo en el mundo nietzscheano sino en la filosofía misma: el eterno retorno nos sería inconcebible e inadmisible si no existiese al menos la remota posibilidad del cambio, de una libertad o libre albedrio real sobre nuestras vidas, de la posibilidad de experimentar algo realmente nuevo, y por su lado, el súper hombre carecería de todo sentido si las vidas humanas estuviesen llenas de imaginación, innovación y originalidad, si el hombre estuviese acostumbrado a trans valorar todas las formas de morales existentes, si el hombre estuviese acostumbrado a romper constantemente con los yugos y cadenas auto impuestos constantemente, este hombre ya sería el súper hombre, y entonces la concepción de súper hombre no existiría, o hubiese quedado sumergida en el tiempo. Es que la eterna repetición de las cosas va de la mano con el pedido y la espera de Nietzsche de que aparezca la novedad, es decir, el quiebre del eterno retorno de lo mismo, la llegada del súper hombre: el eterno retorno son las moralidades, dogmas, ideologías, que rigen el mundo, que a lo largo del tiempo continúan en sus distintas formas, y la llegada de lo nuevo anhelada por Nietzsche es la transvaloración de todos los valores, la venida del súper o trans-hombre. Aquel que se erige con sus propios valores e ideales.

\section{Conclusiones}

Podemos ver como a lo largo de la obra literaria Nietzscheana, o al menos la que logramos abarcar para la presente investigación, el filósofo alemán celebra constantemente la vida. El ejemplo emblemático seria su saludo por el año nuevo en el aforismo doscientos setenta y cuatro (274) de la gaya ciencia. Sin embargo, es el 
mismo filósofo el que critica hasta el hastío casi todas las formas de vida, las practicas a las que recurrimos, las instituciones a las que nos sometemos, los valores y practicas moralizantes a las que acudimos a veces hasta sin darnos cuenta. También encontramos de manera implícita en la mayoría de los casos y de manera repetitiva y constante la concepción del eterno retorno, la concepción del tiempo ejemplificado de manera más circular que lineal. Por último, en las interpretaciones históricas realizadas por otros filósofos sobre la concepción Nietzscheana del eterno retorno nos encontramos como formulaciones y conclusiones que consideramos sumamente correctas, tanto Heidegger con su búsqueda de aportes más concretos que expliquen de cierta manera al ser, como Deleuze con su postulación ética, tocan puntos necesarios para lograr entender o buscar acercarnos a una comprensión propia de la idea del eterno retorno. ¿Es acaso una contradicción decir si a la vida y criticarla en casi todos sus aspectos? ¿Es una contradicción asociar la vida con el movimiento y creer que existe el eterno retorno? O incluso ¿son contradictorias las interpretaciones del eterno retorno realizadas por Heidegger y por Deleuze?

La respuestas más fácil y concreta para estas preguntas nos mostraría que sí, todo esto es una gran contradicción, sin embargo, embriagados en la filosofía nietzscheana podemos comprender que aquello que solemos interpretar como polos opuestos, que la existencia de uno implica la eliminación del otro, en realidad no son más que dos caras o dos partes de lo mismo, lo que comúnmente solemos llamar como contradicción son partes necesarias e incluso dependientes: una vida perfecta, no necesitaría ser afirmada por el vitalismo nietzscheano. Una vida llena completamente estática y sumergida siempre y sin ningún tipo de variación en el eterno retorno no sería capaz de obtener crítica alguna, ya que no se conocería otro tipo de vida. Nietzsche pide por lo nuevo, porque sabe que existe, porque lo ha visto y quiere que sea más constante que variable, dice Si a la vida, porque sabe que esta viene cargada de problemas y dificultades, encuentra belleza en esto, y por eso su concepción del vitalismo, o su forma de vitalismo realiza un giro de tuerca a lo que estábamos acostumbrados. 
Abril 2020.

ISSN 2344-9934

Como conclusión queremos aportar nuestra reinterpretación del eterno retorno nietzscheano de manera concreta, el tiempo es eterno, infinito, podemos entonces ejemplificarlo de manera circular, pero ese tiempo circular debe ser por defecto eternamente creciente, nunca terminaría de dar la vuelta, porque lo infinito y eterno implica la extensión y el crecimiento, por tanto, en el eterno retorno nietzscheano lo que se repite no es concretamente los mismo lugares, o las mismas cosas de manera física o el mismo paisaje, sino que el retorno hace mención a la constante sumisión del hombre a valores morales que no son más que inventos y mentiras propias del hombre. Y en esta sumisión está el hombre de manera individual, sumergido en su rutina y sus instituciones como así también el hombre entendido como colectivos: los pueblos, grupos, sociedades, naciones y demás, sumergidos en lo que pareciera ser un eterno retorno de la opresión, ya sea a la mismas políticas, a los mismos problemas económicos, a la pobreza y demás. ¿Cuántas veces hemos escuchado que es imposible que por ejemplo, África salga alguna vez de la pobreza? Está ahí, presente, el eterno retorno de un pueblo que debe salir al encuentro con el devenir de lo nuevo para romper esos sometimientos.

Llamamos reinterpretación positiva a la que hemos tratado de realizar en el presente trabajo ya que consideramos que Nietzsche nos aporta con su visión del eterno retorno la posibilidad implícita de romper con el mismo, nos hace preguntar qué estamos haciendo con nuestras vidas, nos hace pensar cuál es la manera en la que nos sentiríamos realmente vivos. Nadie podría aceptar vivir una y mil veces más lo mismo, sin embargo este cuestionamiento nos hace pensar y tratar de vivir de tal manera que lo nuevo se apodera de nosotros, que nuestra vida está en constante movimiento, es decir rompiendo en cada paso con las cadenas que nos someten, y por tanto no solamente estaríamos rompiendo con el eterno retorno sino que estaríamos haciendo de lo nuevo, parte de nosotros.

El eterno retorno es una de las ideas filosóficas más poderosas, chocantes e impactantes de toda la historia, al paso del tiempo sigue aun generando un gran dolor de cabeza a los filósofos (entendido como cualquiera, que en cualquier lugar se ponga a cuestionar y hacer filosofía) que han tratado de entenderla durante cientos de años. 
No fue ni es nuestra intención resolver una especie de enigma diciendo qué es lo que Nietzsche quiso escribir, primero, porque no creemos en las interpretaciones únicas y correctas, sobre todo con Nietzsche que pareciera pedirnos constantemente lograr ideas e interpretaciones propias, y segundo porque intentamos plasmar algunas ideas alrededor del eterno retorno que puedan servir de manera práctica a aquel que se acerque a este texto, relacionar esta idea filosófica con nuestra vida concreta no nos dará respuestas cerradas ni finales, pero sí, nos permitirá hacer de la filosofía parte real y practica de nuestras vidas, y esto también abrirá la puerta a nuevas interpretaciones o formas de llevar a la acción aquellas ideas de la filosofía que nos vienen rascando la cabeza hace miles de años.

\section{Bibliografía}

- DELEUZE, G. (2000) Nietzsche. Trad. Isidro Herrera y Alejandro del Rio. Arena Libros, Madrid.

- DELEUZE, G. (2002) Diferencia y repetición. Trad. María Silvia Delpy y Hugo Beccacece, Talleres Gráficos Color Efe, Argentina.

- DELEUZE, G. (1998) Nietzsche y la filosofía. Trad. Carmen Artal, Editorial Anagrama, España.

- $\quad$ NIETZSCHE, F. La ciencia jovial. Trad. José Jara, Monte Ávila, Venezuela, 1990.

- NietzSCHe, F. (2003) Así Hablo Zaratustra. Trad. Andrés Sánchez Pascual, Alianza Editorial, España.

- NIetzSCHE, F. (2005) Ecce Homo. Trad. Andrés Sánchez Pascual, Alianza Editorial, España.

- HEIDEgGeR, M. (2013) Nietzsche. Trad. Juan Luis Vermal, Editorial Ariel, España. 